\title{
Interviewing as a Data Collection Method: A Critical Review
}

\author{
Hamza Alshenqeeti ${ }^{1}$ \\ ${ }^{1}$ Newcastle upon Tyne, United Kingdom \\ Correspondence: Hamza Alshenqeeti, Newcastle upon Tyne, United Kingdom. E-mail: hza999@hotmail.com
}

Received: January 26, 2014

Accepted: March 29, 2014

Online Published: March 31, 2014

doi:10.5430/elr.v3n1p39

URL: http://dx.doi.org/10.5430/elr.v3n1p39

\begin{abstract}
Through this paper I critically assess the value and limitations of interviewing as a research instrument. Therefore, my discussion, which would be based on methodological issues allied with the use of interviews in qualitative social science research, is two-fold. Firstly, I briefly review the literature concerning the use of interviews, discuss interviews' types and illustrate the differences between these types. Then, issues regarding interviewing in practice will be discussed, ending this part with a brief review of the notion of interviewing in linguistic research. Secondly, a critical evaluation of the method will be presented, including a consideration of its usefulness and pitfalls, followed by discussing issues of validity and reliability of using interviews as a research instrument. To end with, ethical issues concerning the use of interviews will be discussed before drawing on our conclusion.
\end{abstract}

Keywords: Research method, Interviewing, Qualitative interviewing

\section{Introduction}

Needless to say, research methods in social science research are an essential part of any research project as they determine its success, validity and reliability. Stemming from an interest in thorough understanding of human behaviour, social scientists tend to use qualitative research aiming to accumulate a detailed account of human behaviour and beliefs within the contexts they occur in (Rubin \& Rubin, 2005). Furthermore, with the use of non-numerical data, this line of research seeks to explore and describe the 'quality' and 'nature' of how people behave, experience and understand. Further to linking people's actions to their beliefs, Brown (2005: 485) adds that "one of the great strengths often cited for qualitative research is its potential for forming hypotheses". As noted by Dörnyei, (2007: 132), qualitative data are 'most often' collected by researchers through interviews and questionnaires. However, interviews -compared to questionnaires- are more powerful in eliciting narrative data that allows researchers to investigate people's views in greater depth (Kvale, 1996; 2003). In a similar vein, Cohen et al (2007: 29) add that interviewing is "a valuable method for exploring the construction and negotiation of meanings in a natural setting".

That is, the value of interviewing is not only because it builds a holistic snapshot, analyses words, reports detailed views of informants; but also because it enables interviewees to "speak in their own voice and express their own thoughts and feelings" (Berg, 2007: 96). Moreover, interviewing, as well as other qualitative approaches to social science research, differs from quantitative methods in the sense of its ability to analyse the resulting data making an allowance for participants' social life. Aiming to employ interviews in my future research, through this paper I would critically assess the value and limitations of interviewing as a research instrument. Therefore, my discussion, which would be based on methodological issues allied with the use of interviews in qualitative social science research, is two-fold. Firstly, I briefly review the literature concerning the use of interviews, discuss interviews' types and illustrate the differences between these types. Then, issues regarding interviewing in practice will be discussed, ending this part with a brief review of the notion of interviewing in linguistic research. Secondly, a critical evaluation of the method will be presented, including a consideration of its usefulness and pitfalls, followed by discussing issues of validity and reliability of using interviews as a research instrument. To end with, ethical issues concerning the use of interviews will be discussed before drawing on our conclusion. Interestingly, by and large, this essay is expected to enrich my future research in terms of the appropriate use and analysis of interviews.

\section{Literature Review}

In the field of social science research, the usefulness of interviews has long been recognized. That is, as qualitative researchers tend to provide detailed descriptions of individuals and events in their natural settings, interviewing has 'usually' been thought of as a key factor in research design (Weiss, 1994). In a similar vein, Kvale (1996) 
interestingly points out that, as such events are not often directly 'observable'; talking to people would be one of the most effective methods for attaining and exploring such constructs. More specifically, as interviews are interactive, interviewers can press for complete, clear answers and can probe into any emerging topics. Hence, interviewing is expected to broaden the scope of understanding investigated phenomena, as it is a more naturalistic and less structured data collection tool.

According to Kvale (1996: 174) an interview is "a conversation, whose purpose is to gather descriptions of the [life-world] of the interviewee" with respect to interpretation of the meanings of the 'described phenomena'. In a similar vein, Schostak, (2006: 54) adds that an interview is an extendable conversation between partners that aims at having an 'in-depth information' about a certain topic or subject, and through which a phenomenon could be interpreted in terms of the meanings interviewees bring to it. Accumulating such meanings can be done in various ways, of which one-on-one interviews are the most common. Besides one-on-one interviews, focus groups interviewing is also popular (Marshall \& Rossman, 2006). Additionally, research has shown that four types of interviews are frequently employed in social sciences. The first is the structured interview, whose key feature is that it is mostly organised around a set of predetermined direct questions that require immediate, mostly 'yes' or 'no' type, responses. Thus, in such an interview, the interviewer and interviewees would have very little freedom (Berg, 2007). Accordingly, it can be argued, that this type of interviews is similar to the 'self-administered' quantitative questionnaire in both its form and underlying assumptions.

The second type of interviews is the open-ended (unstructured) interview. Gubrium \& Holstein (2002) point out that, unlike the structured interview, this kind of interviewing is an open situation through which a greater flexibility and freedom is offered to both sides (i.e. interviewers and interviewees), in terms of planning, implementing and organising the interview content and questions (p. 35). Therefore, the interviewer here would be more "keen to follow up interesting developments and to let the interviewee elaborate on various issues" (Dörnyei, 2007: 136). Third, is the semi-structured interview, which is a more flexible version of the structured interview as "it allows depth to be achieved by providing the opportunity on the part of the interviewer to probe and expand the interviewee's responses" (Rubin \& Rubin, 2005: 88). When undertaking such interviews, researchers recommend using a basic checklist (see Berg, 2007) that would help covering all relevant areas (i.e. research questions). The advantage of such a checklist, as Berg considers, is that it "allows for in-depth probing while permitting the interviewer to keep the interview within the parameters traced out by the aim of the study" (ibid,p. 39). For the purpose of my research, I opted for this type of interviews as it would allow covering various issues concerning my study (Note 1). Fourthly, focus group interviewing which is, according to Barbour \& Schostak (2005), “...an interviewing technique in which participants are selected because they are a purposive, although not necessarily representative, sampling of a specific population, this group being 'focused' on a given topic" (p. 46).

Excluding personal concerns, however, this type of interviewing requires "skilful chairing and attention to the physical layout of the room and group size" (Hermanowicz, 2002: 490). In sum, although focus groups can be suitable for investigating complex behaviour, it can sometimes be very time-consuming and effortful process. Smithson (2000: 116) claims that "the use of focus groups as a quick data-gathering method, ending up with some 'sound-bite' quotations to illustrate themes, ignores the complexities of focus group behaviour". Yet, Berg (2007: 45) argues that a particular strength of this type of interviewing is that participants may "...develop ideas collectively, bringing forward their own priorities and perspectives, to create theory grounded in the actual experience". By and large, I would argue that the characteristics of using interviews would make it more interesting to employ in qualitative inquiries. Meanwhile, however, the interviewing process itself can be complex and even difficult to follow. To put it in Schostak's (2006: 92) words, an interview “....is not a simple tool with which to mine information. It is [rather] a place where views may clash, deceive, seduce, enchant". Therefore, in line with Schostack, I would suggest that one should not use interviews simply because they think that it might be an easy way of conducting research. That is, researchers in the social science field should consider the characteristics of interviewing before designing, applying, and analysing interviews.

\section{Background}

Interviewing, Dörnyei (2007) argues, is 'a natural and socially acceptable' way of collecting data as it can be used in various situations covering a variety of topics. In line with this, as recommended by various researchers (e.g. Bell, 1987; Kvale, 1996; Berg, 2007), interviewing should be adopted as a tool for social research as it facilitates obtaining 'direct' explanations for human actions through a comprehensive speech interaction. However, other researchers (e.g. Schostak, 2006), are of the view that:

Listening to people's lives, recording their experiences, their moments of crisis, their frailties, their intimacies; these 
are the challenges to the researcher. What is this moment of listening? And how does it 'translate' into the text of the transcript? How is the text then to be read? By focusing upon that moment of engagement between people where each attends to and addresses the other, this moment of engagement is critical for every dimension of what it means to be human, [...] (ibid: 11).

Resolutely, for someone like Schostack $(2002 ; 2006)$, although interviewing is relatively a simple methodology to utilize; interviewing challenges are enough for calling researchers' attention. In line with this, I can only add that although being a prevalent research instrument (cf. Creswell, 2009), it does not mean that interviews should not (steadily and cautiously) be shaped in terms of first how they are used, and then how they are reported. That is, interviews should not only be illustrative, but reflective and critical. In the sections that follow, a more detailed discussion of these two key aspects is presented in turn.

\section{Interviewing in Practice}

\subsection{Conducting Interviews}

According to Dörnyei (2007), a 'good' qualitative interview has two key features: “(a) it flows naturally, and (b) it is rich in detail" (p. 140). To attain this, it is therefore necessary for researchers to remember that they are there to 'listen' not just speak (ibid). In addition, researchers should not only be neutral, but also at the same time, they should take Richards's (2003) 'golden advice' which addresses all types of interviewing: interviewers should "always seek the particular" (p. 53). In doing so, the interviewer should establish an appropriate atmosphere through which his/her interviewees would feel more at ease and thus talk freely. Besides, Barbour and Schostak (2005: 42-43) identify the following key concepts that researchers should also take into consideration when using interviews as a tool for data collection:

Power relation: this refers to the interrelated power within the interview. Such power may (intentionally or unintentionally), but not necessarily, emerge from the interviewer's side towards his/her interviewees. Extending the interview, therefore, would help balancing this relationship.

- Value: this refers to the value of the interview itself, and the value of the interviewees' words.

- trust: this refers to the extent to which the research guarantees objectivity, accuracy and honesty.

- Meaning: this refers to the meaning the interviewer intends to convey. This process might sometimes be incorrectly done, and therefore an alternative truth or reality might be declared.

- Wording: this refers to the wording of questions asked in the interview. Barbour and Schostak (2005: 43) justly remark that "the shorter the interviewer's questions and the longer the subject's answers, the better an interview is".

Berg (2007: 210) suggests that it is important for interviewers to maintain their "interviewee's motivation by keeping boredom at bay". This can be done in various ways, for example by keeping to a minimum demographic (e.g. age) and personal (e.g. income) questions. As to its typical duration, as Schostack (2002) notes, an interviewer would be expected to spend at least half an hour to unravel the investigated phenomenon. Yet, this overlooks the question that Dörnyei (2007) refers to as often not mentioned in research projects, which is weather to make a single or multiple interview sessions. Obviously, the answer to this is based on the research questions, sources available, and amount of data needed. Furthermore, Talmy (2010) stresses that interviewees should be given a chance at the end of the interview, to bring up comments or ask questions. Additionally, researchers should, at this point, re-express their gratitude to their interviewees and discuss ways of future contact. Importantly, moreover, it would be beneficial for researchers to have a piloting session before carrying out their interviews as this will not just refine the interview content, but also determine its feasibility and usefulness as a research instrument (Creswell, 2009).

\subsection{Analysing Interview Data}

Overwhelming some researchers, qualitative interviews tend to generate large amounts of data (Neuman, 2007). That is, as Dörnyei (2007) indicates, a one-hour interview may approximately take up to six to seven hours to transcribe, and around fifty pages of transcript. However, to begin with, analysis can be done through coding. Two steps of coding have widely been discussed in social science research: a) generating meaningful data units; and b) classifying and ordering these units. Accordingly, such a process is expected to deliberately reduce the amount of data collected. Creswell (2009) notes that the analysis process should also be reflexive, i.e. including the researcher's interactional experience with interviews. In sum, there is no fixed method of analysing interview data in the literature, yet, researchers should cautiously deal with it as it affects not only the quality of an interview, but the validity, reliability of the whole research. 


\subsection{Reporting Interviews}

Reporting an interview is a major step that eventually has to be done; however, the nature of the reporting is somewhat decided by the nature of the interviewing (Bell, 1987). For instance, a structured interview, which may yield numerical data, can be reported succinctly in tables and graphs, whilst an open-ended interview which would yield word-based accounts, may take up considerably more space (ibid). Kvale (1996:263) suggests several elements of an interview report:

- an introduction that includes the main themes and contents;

- an outline of the methodology and methods (from designing to interviewing, transcription and analysis);

- the results (the data analysis, interpretation and verification); and

- a discussion.

In a similar vein, Holliday (2007: 91) asserts that to begin with, it is necessary for the researcher to describe the research procedures, and the relevance of the research questions and their applicability to the use of the method. However, reporting is not just of what has been said, it has to include discussing and justifying the information and answers given (Neuman, 2007). Furthermore, some of the respondents' answers can be quoted as they would provide remarkable and 'invaluable interpretations' (Bechhofer \& Paterson, 2000: 160).

\section{Interviewing in Linguistics}

Interviews have widely been used as a method of data collection in recent linguistic research. Various studies (e.g. Dörnyei \& Skehan, 2003; Nazari, 2007; Talmy, 2010) showed that interviews are one, if not the primary, method of investigating linguistic phenomena. More specifically, Block (2000: 757) states that the rationale behind using interviews in linguistic research is "to take research participants 'at their word' ...[that is] to offer presentation of data plus content analysis, but no problematization of the data themselves or the respective roles of interviewers and interviewees". As noted by Paylenko (2007), when using narrative data, people's description of their linguistic behaviour (e.g. language learners' reticence) may not always reflect the reality. He, therefore, maintains that interviewing might be the successful alternative technique in testing linguistic phenomena. However, although this may indicate that interviewing is more than just describing facts; presenting events might differ greatly depending on the language of telling (Richards, 2009). Yet, to overcome this, Mackay and Gass (2005: 174) state that "...depending on the research questions and resources available, interviews can be conducted in the interviewee's L1, thus removing the concerns about the proficiency of the [interviewer] impacting quality and quantity of the data provided". Additionally, however, analysing interview linguistic data can be challenging with regard to the co-constructed nature of oral responses. That is, although some researchers would analyse the narratives as if they would do any oral or written analysis, this method tends to ignore the interactional influence on the presented data. Paylenko (2007) argues that analysing interviews using traditional approaches is more likely to create a distance between the interviewer and his/her interviewee, which would therefore produce an incomplete snapshot of the investigated phenomenon. Yet, to resolve the issue, I would follow Sidnell (2010) who suggests using an interactional/conversational approach (e.g. CA (Note 2)) for analysing interviews data.

Apart from this, my future research interviewees will all be students and according to Tierney and Dilley (2001), interviewing students is of great significance as it would include them and their views in the learning process. Besides, as Tierney and Dilley point out, until early $20^{\text {th }}$ century, students' views were largely ignored. In all, for the investigation of linguistic phenomena, more effort should be made not just before analysing interview data, but even before conducting the interview itself. Furthermore, it would be valuable for researchers in the field, to consider the interview's non-linguistic aspects, e.g. the interviewees' body language, gestures and other sources of 'unsaid' data, as they represent an interesting source of research information (Tamly, 2010).

\section{Critical Evaluation of the Method}

According to Blaxter et al (2006: 172), it is worthwhile doing interviews because it offers researchers the opportunity to uncover information that is "probably not accessible using techniques such as questionnaires and observations". Moreover, they add that interviewing is not merely a data collection tool, it is rather a natural way of interaction that can take place in various situations (ibid: 177). Additionally, Dörnyei (2007: 143) argues that with the presence of the interviewer, mutual understanding can be ensured, as the interviewer may rephrase or simplify questions that were not understood by his/her interviewees. As a result, more appropriate answers and, subsequently, more accurate data will be reached. Additionally, this data can be recorded and reviewed several times by the researcher (when necessary) to help producing an accurate interview report (Berg, 2007). Besides, with the existence 
of various cheap and prudent tape-recorders, researchers can record the respondent's words with greater accuracy than that achieved through obtrusive and disruptive 'on-the-spot' note-taking (Hermanowicz, 2002). Interestingly, therefore, this would relieve the researcher from any subsequent attempts to reconstruct what the interviewee has said. Above and beyond, interviewing -compared to other methods- is known to be an economical method as costs for individuals 'using it for research purposes are reduced' (Neuman, 2007).

Obviously, these advantages have made interviewing an increasingly attractive method of data collection. However, like any other research tool, interviews can be fraught with drawbacks. Hermanowicz (2002: 498) remarks that "while interviewing is among the most central, revealing and enjoyable methods that one can use in research, it is deceptively difficult". Besides, Hammersley \& Gomm (2008: 100) add that researchers should remember that:

"what people say in an interview will indeed be shaped, to some degree, by the questions they are asked; the conventions about what can be spoken about;...[... ...by what time they think the interviewer wants; by what they believe he/she would approve or disapprove of".

As such a comment suggests, it seems that, interviewees will only give what they are prepared to reveal about their perceptions of events and opinions. These perceptions, however, might be subjective and therefore change over time according to circumstance. Such responses, thus, might be at a considerable distance from 'reality' (Note 3). Walford (2007: 147) argues that "interviews alone are an insufficient form of data to study social life". That is, as both interviewer and interviewee may have incomplete knowledge or even faulty memory. Hence, this lets us question the appropriateness of using interviews as the only transparent means of eliciting data that would inform understandings of the meanings interviewees make of their lived experiences (Potter and Hepburn, 2005). Undoubtedly, furthermore, large amounts of data are expected to be revealed via interviews. Therefore, we should follow Scheurich (1995: 249) who stresses that it is important for interviewers to "highlight the baggage they get out of the interview". In addition, interviews have also been criticised (Robson, 2002: 94) as being time-consuming with regard to both data collection and analysis because they need to be transcribed, coded and possibly translated as was the case in the present study. In sum, Brown (2001) interestingly reviews the advantages and disadvantages of interviewing; as follows (Note 4):

Table 1. Advantages and disadvantages of interviewing

\begin{tabular}{l|l}
\hline \multicolumn{1}{c|}{ Advantages } & \multicolumn{1}{c}{ Disadvantages } \\
\hline high return rate & time-consuming \\
\hline ewer incomplete answers & small scale study \\
\hline can involve reality & never $100 \%$ anonymous \\
\hline controlled answering order & potential for subconscious bias \\
\hline relatively flexible & potential inconsistencies \\
\hline
\end{tabular}

In conclusion, with regard to the advantages and disadvantages of interviews and to make my position clear, I would follow Robson (2002) and Ho (2006) who maintain that although interviewing is a powerful way of getting insights into interviewee's perceptions, it can go hand in hand with other methods "providing in-depth information about participants' inner values and beliefs" (Ho, 2006: 11). For instance, using observation as a supplement to interviews would allow researchers investigate participants' external behavior and internal beliefs. Therefore, although it depends on the research questions, I would argue that using more than one data collection instrument would help obtaining richer data and validating the research findings.

\section{Validity and Reliability}

Indeed, issues of validity and reliability of research instruments are of great of great significance to the findings of any scientific research. Moreover, as Dörnyei (2007) adds, validity and reliability issues serve as guarantees of the results of the participants' performances. In its broader context, validity refers to the degree to which a study reflect the specific concepts it aims to investigate. Two types of validity are discussed in social science literature: internal and external (Berg, 2007). Internal validity refers to the extent to which an investigation is actually measuring what it is supposed to measure. This type of validity answers the question: Are the differences found related to the measurement?; while external validity answers the question: Can the findings be generalised? Yet, in order to maintain this, researchers should consider a number of factors. Cohen et al (2007) propose the following factors which may lead to higher validity by minimising the possibility of bias:

the attitude, views and prospects of the interviewer;

a tendency for interviewer to see the interviewee on his/her own merits; 
a tendency for interviewers to seek answers to support their preconceived notions;

misperceptions on the part of the interviewer with regard to what the interviewee is saying; and

misunderstanding on the part of the interviewee with regard to what is being asked (p. 150).

On the other hand, reliability refers to the extent to which a research instrument yields the same results on repeated trials. Yet, Brewerton and Millward (2001: 74) justifiably argue that interviews have poor reliability: “...due to their openness to so many types of bias, interviews can be notoriously unreliable, particularly when the researcher wishes to draw comparisons between data sets". In line with this, Creswell (2009: 153) claims that interviewing reliability is 'elusive' and he even adds that "no study reports actual reliability data". In sum, researchers should follow techniques that would help maintaining the validity and reliability of interviewing. These can be:

avoiding asking leading questions

taking notes not just depending on tape recorders

conducting a pilot interview; and

giving the interviewee a chance to sum up and clarify the points they have made.

\section{Ethical Considerations}

When it comes to dealing with human participants, research projects should rigorously follow ethical considerations. According to Cohen et al (2007), as interviews are considered an intrusion into respondents' private lives with regard to time allotted and level of sensitivity of questions asked; a high standard of ethical considerations should be maintained. Therefore, ethical issues should be considered at all stages of the interview process. That is, participants should provide their informed consent before participating in the interview: a key step that researchers should adhere to throughout the whole research project. However, an ethical challenge to researchers would be the openness and intimacy of the interview situation as it may lead respondents to disclose information that they may later regret, and there is a risk that the interaction may become a quasi-therapeutic relationship for which most researchers might not have been trained. Therefore, to protect the participants' rights and to avoid causing them any harm, researchers should assure that the collected data will be strictly confidential and anonymous. More importantly, however, participants should be told that their participation in the interview is entirely voluntary, and that they can withdraw at any time. With regard to my future research, appropriate consent forms will be designed; translated into Arabic (if needed); and distributed among the participants to sign. Furthermore, a brief explanation of my study's nature and the participants' rights will, concurrently, be distributed.

\section{Conclusion}

In sum, the present paper has addressed the main issues related to the role of interviews in social science research, where an attempt has been made to critically assess the value and limitations of its use. Besides, however, although research on using interviews has long been an expanding area of study, it might be accompanied with a number of conceptual problems that need to be constantly considered. Therefore, I would recommend that researchers should consider developing skills of using and analyzing interviews. In a nutshell, researchers should however, choose the method that answers their research questions best, taking into consideration that the more accurate the researchers are when conducting and analysing the data, the more accurate the findings would be.

\section{References}

Barbour, R. \& Schostak, J. F. (2005). Interviewing and Focus Groups. In: B. Somekh \& C. Lewin, (eds.) Research Methods in the Social Sciences (pp. 41-48). London: Sage.

Bechhofer, F. \& Paterson, L. (2000). Principles of Research Design in the Social Sciences. London: Routledge.

Bell, J. (1987). Doing Your Research Project: a Guide for First-time Researchers in Education and Social Science. Milton Keynes: Open University Press.

Berg, B. L. (2007). Qualitative research methods for the social sciences. London: Pearson.

Blaxter, L., Hughes, C. \&Tight, M. (2006). How to Research. (3 ${ }^{\text {rd }}$ Ed.) New York: McGraw-Hill Education.

Brinkmann, S. \& Kvale, S. (2005). Confronting the ethics of qualitative research. Journal of Constructivist Psychology, 18, 157-181. http://dx.doi.org/10.1080/10720530590914789

Brown, D. J. (2001). Using Surveys in Language Programs. Cambridge: Cambridge University Press. 
Brown, J. D. (2005). Research methods for applied linguistics. In: A. Davies and C. Elder, (Eds.), The Handbook of Applied Linguistics (pp. 476-500). Oxford, UK: Blackwell.

Cohen, L., Manion, L., \& Morison, K. (2007). Research Methods in Education. (6 $6^{\text {th }}$ ed.). London: Routledge.

Creswell, J. W. (2009). Research Design: Qualitative, Quantitative, and Mixed Methods Approaches. (3 ${ }^{\text {rd }}$ Ed.). Thousand Okas, CA: Sage.

Dörnyei, Z. (2007). Research Methods in Applied Linguistics: Quantitative Qualitative, and Mixed Methodologies. Oxford: Oxford University Press.

Dörnyei, Z. \& Skehan, P. (2003). Individual differences in second language learning. In: C. J. Doughty and M.H. Long, (Eds), The Handbook of Second Language Acquisition (pp. 589- 630). Malden, MA: Blackwell. http://dx.doi.org/10.1002/9780470756492.ch18

Drew, P., Raymond, G. \& Weinberg, D. (Eds.), (2006). Talk and Interaction in Social Research Methods. London: Sage.

Gubrium, J. F. \& Holstein, J. A. (Eds.). (2002). Handbook of Interview Research: Context and Method. Thousand Oaks, CA: Sage.

Hammersley, M. \& Gomm, R. (2008). Assessing the radical critiques of interviews. In: M. Hammersley, (Ed.), Questioning Qualitative Inquiry: Critical Essays (pp. 89-100) London: Sage.

Hermanowicz, J. C. (2002). The great interview: 25 strategies for studying people in bed. Qualitative Sociology. 25(4): 479-499. http://dx.doi.org/10.1023/A:1021062932081

Ho, D. (2006). The focus group interview: Rising the challenge in qualitative research methodology. Australian Review of Applied Linguistics, 29(1): 5. 1-19.

Holliday, A. R. (2007) Doing and Writing Qualitative Research. (2 ${ }^{\text {nd }}$ Ed.). London: Sage

Kvale, S. (1996). InterViews: An introduction to qualitative research interviewing. Thousand Oaks, CA: Sage.

Kvale, S. (2003). The psychoanalytic interview as inspiration for qualitative research. In P. M. Camic, J. E. Rhodes, \& L. Yardley (Eds.), Qualitative research in psychology (pp. 275- 297). Washington, USA: American Psychological Association.

Kvale, S. \& Brinkmann, S. (2009). Interviews. Learning the Craft of Qualitative Researcch Interviewing. (2 ${ }^{\text {nd }}$ Ed.). Thousand Okas, CA: Sage.

Mackay, A. \& Gass, S. (2005). Second Language Research: Methodology and Design. Mahwah, New Jersey: Lawrence Erlbaum Associates.

Marshall, C. \& Rossman, G. B. (2006). Designing Qualitative Research. (4 ${ }^{\text {th }}$ Ed.). Thousand Oaks, CA: Sage.

Nazari, A. (2007). EFL teachers' perception of the concept of communicative competence. ELT Journal, 61(3): 202-210. http://dx.doi.org/10.1093/elt/ccm027

Neuman, W. L. (2007). Social Research Methods: Qualitative and Quantitative Approaches. (6 ${ }^{\text {th }}$ Ed.) Boston: Pearson.

Patton, M. Q. (2002). Qualitative Research and Evaluation Methods. ( $3^{\text {rd }}$ Ed.). Thousand Oaks, CA: Sage.

Potter, J. \& A. Hepburn. (2005). Qualitative interviews in psychology: Problems and possibilities. Qualitative Research in Psychology, 2: 281-307. http://dx.doi.org/10.1191/1478088705qp045oa

\section{Notes}

Note 1. My research revolves around the issue of using language learning strategies by Arab learners of English for Specific Purposes (ESP) both in and outside of the classroom.

Note 2. Conversation Analysis (CA) is a talk-in-interaction approach that aims to "describe, analyse, and understand talk as a basic and constitutive feature of human social life" (Sidnell, 2010: 1).

Note 3. Even with reserving the epistemological question of whether or not there is an ultimate 'reality'.

Note 4. The table is adapted from Brown (2001: 75). 